\section{Effects of maternal medication on long-term outcome in congenital heart block remain to be established. Response to: 'Comorbidity and long-term outcome in patients with congenital heart block and their siblings exposed to Ro/ SSA autoantibodies in utero' by Satis et al}

We thank Satis and colleagues for opening the discussion on a potential influence of maternal immunomodulatory treatment on the long-term outcome of congenital heart block $(\mathrm{CHB})^{1}$ and welcome their questions to help clarify some aspects of our study. ${ }^{2}$ Whether immunomodulatory treatment administered to the mother-as part of her own rheumatic disease treatment or intended to ameliorate the fetal cardiac inflammation in $\mathrm{CHB}-$ influences any outcome in CHB is a current matter of debate. Satis and colleagues cite several studies supporting a role for maternally administered immunomodulatory treatment to improve fetal outcome, but other investigators present a less hopeful view. ${ }^{3-5}$ Our own experience in prospectively followed Ro/SSA-positive pregnancies, allowing prompt transplacental administration of fluorinated steroids (betamethasone) on progression from normal sinus rhythm to second or third-degree atrioventricular (AV) block and/ or endocardial fibroelastosis, is that such treatment rarely reverses a third-degree AV block (a temporary effect in one of five cases) but can reverse incomplete blocks and results in higher ventricular rate and delays the need for pacemaker implantation in complete AV block. ${ }^{6}$ In all, our single-centre data support a role for maternally administered immunomodulatory treatment in ameliorating the fetal condition. However, in the current epidemiological study on long-term outcome, exhaustive information on treatment was not available and was thus not included in the article. Notably though, the practice to treat incomplete or complete AV block in our country was not introduced until after year 2000, the effect of which may not be captured in the discussed study. ${ }^{2}$ A follow-up study investigating preventive procedures and predictors of fetal outcomes in Ro/SSA-positive pregnancies is under way.

Satis and colleagues also raise the question whether any patients with $\mathrm{CHB}$ healed, as not all individuals in the $\mathrm{CHB}$ cohort had records of diagnoses within 'Other forms of heart disease' (I30-I52) during the follow-up period. Rather than relating to individuals recovering from the condition or coding errors, the discrepancy is related to the fact that the International Classification of Diseases (ICD) code for congenital heart block is Q24.6 - - that is, not included in the ICD block. However, as stated in the article, all individuals included in the study had complete $\mathrm{CHB}$ confirmed by their treating clinician.
Johannes Mofors, ${ }^{1}$ Sven-Erik Sonesson, ${ }^{2}$ Marie Wahren-Herlenius $\odot{ }^{1}$

${ }^{1}$ Division of Rheumatology, Department of Medicine, Karolinska Institutet, Karolinska University Hospital, Stockholm, Sweden

${ }^{2}$ Department of Women's and Children's Health, Karolinska Institutet, Karolinska

University Hopsital, Stockholm, Sweden

Correspondence to Marie Wahren-Herlenius, Department of Medicine, Karolinska Institutet, Stockholm 171 77, Sweden; marie.wahren@ki.se

Handling editor Josef S Smolen

Contributors All authors wrote the paper.

Funding The authors have not declared a specific grant for this research from any funding agency in the public, commercial or not-for-profit sectors.

Competing interests None declared.

Patient consent for publication Not required.

Provenance and peer review Commissioned; internally peer reviewed.

(c) Author(s) (or their employer(s)) 2020. No commercial re-use. See rights and permissions. Published by BMJ.

\section{Check for updates}

To cite Mofors J, Sonesson S-E, Wahren-Herlenius M. Ann Rheum Dis 2020;79:e95.

Received 10 June 2019

Accepted 15 June 2019

Published Online First 4 July 2019

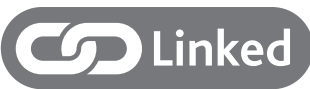

- http://dx.doi.org/10.1136/annrheumdis-2019-215542

Ann Rheum Dis 2020;79:e95. doi:10.1136/annrheumdis-2019-215677

ORCID iD

Marie Wahren-Herlenius http://orcid.org/0000-0002-0915-7245

\section{REFERENCES}

1 Satış H, Bilici Salman R, Avanoğlu Güler A, et al. Comorbidity and long-term outcome in patients with congenital heart block and their siblings exposed to Ro/SSA autoantibodies in utero. Ann Rheum Dis 2020;79:e94.

2 Mofors J, Eliasson H, Ambrosi A, et al. Comorbidity and long-term outcome in patients with congenital heart block and their siblings exposed to Ro/SSA autoantibodies in utero. Ann Rheum Dis 2019;78:696-703.

3 Eliasson H, Sonesson S-E, Sharland G, et al. Isolated atrioventricular block in the fetus: a retrospective, multinational, multicenter study of 175 patients. Circulation 2011;124:1919-26.

4 Izmirly PM, Saxena A, Sahl SK, et al. Assessment of fluorinated steroids to avert progression and mortality in anti-SSA/Ro-associated cardiac injury limited to the fetal conduction system. Ann Rheum Dis 2016;75:1161-5.

5 Levesque K, Morel N, Maltret A, et al. Description of 214 cases of autoimmune congenital heart block: results of the French neonatal lupus syndrome. Autoimmun Rev 2015;14:1154-60.

6 Sonesson S.-E., Ambrosi A, Wahren-Herlenius M. Benefits of fetal echocardiographic surveillance in pregnancies at risk of congenital heart block: single-center study of 212 anti-Ro52-positive pregnancies. Ultrasound Obstet Gynecol 2019;44. 